\title{
Gasification of Miscanthus X Giganteus in catalytic conditions Production of syngas, preliminary results
}

\author{
Rudy Michel ${ }^{1}$, René Gruber ${ }^{1}$, Philippe Burg ${ }^{1}$, Sergio Rapagnà ${ }^{2}$, \\ Giuseppe Mazziotti Di Celso ${ }^{2}$ and Claire Courson ${ }^{3}$ \\ ${ }^{1}$ Laboratoire de Chimie et de Méthodologies pour l'Environnement - EA 4164 \\ Université Paul Verlaine, 1 Bd Arago, technopôle 2000, 57078 Metz cedex 3 (France) \\ ${ }^{2}$ Universita degli studi di Teramo, Departimento di Scienze degli Alimenti \\ Via Carlo R. Lerici, 64023 Mosciano S. Angelo (TE) (Italy) \\ ${ }^{3}$ Laboratoire des Matériaux, Surfaces et Procédés pour la Catalyse (LMSPC) \\ Université Louis Pasteur, 25 rue Becquerel 67087 Strasbourg Cedex 2 (France) \\ rudy.michel@univ-metz.fr
}

The continuous increase in $\mathrm{CO}_{2}$ content in the atmosphere, mainly due to the combustion of fossil fuels, is predicted to lead to the global warming. Biomass is considered as a promising renewable energy source. The conventional method for the production of synthesis gas from biomass is gasification. The gasification of biomass provides the most attractive solution for the introduction of biomass in decentralised power production.

Conversion of biomass to synthesis gas becomes more and more important in terms of renewable energy sources. Moreover, in the different processes of gasification, the main problems remain the total removal of tars and light hydrocarbons like methane formed during the thermal treatment.

In fact, it is necessary to obtain a very pure and stoichiometric mixture of $\mathrm{CO}$ and $\mathrm{H}_{2}$ that can be used for the preparation of hydrocarbons via the Fischer-Tropsch synthesis. To solve this problem, beside temperature reaction process, it is also necessary to select an appropriate and efficient catalyst. Among the factors affecting the activity of the tar decomposition reactions, the positive catalytic role of iron has been demonstrated ${ }^{1,2}$. This good catalytic behaviour is exhibited by olivine, an iron-containing mineral, in a systematic study of bed inventories for the biomass gasification process. As reported extensively in the literature, biomass steam gasification (performed in main cases in fluidised bed reactors) results in the conversion of carbonaceous materials to permanent gases $\left(\mathrm{H}_{2}, \mathrm{CO}, \mathrm{CO}_{2}, \mathrm{CH}_{4}\right.$, and light hydrocarbons), chars and tars ${ }^{1}$. The addition of steam water as gasifying agent and catalyst in gasification process makes it possible to obtain high-grade product ${ }^{3}$.

This study concerns the first results obtained in Miscanthus $\mathrm{X}$ Giganteus (MxG) gasification. Since about ten years, several works are devoted to the valorisation of $\mathrm{MxG}$ as culture, materials, combustion or pyrolysis. 
Table 1: Composition of Miscanthus X Giganteus

\begin{tabular}{|c|c|c|c|c|c|c|c|}
\hline \multicolumn{8}{|c|}{ Composition $\%$ of dry matter } \\
\hline \multicolumn{2}{|c|}{ Cellulose } & \multicolumn{3}{|c|}{ Hemicellulose } & \multicolumn{2}{|c|}{ Lignin } & Ash \\
\hline \multicolumn{2}{|c|}{43} & \multicolumn{3}{|c|}{27} & & 24 & $<4$ \\
\hline \multicolumn{3}{|c|}{$\begin{array}{c}\text { Ultimate } \\
\text { Analysis (\%) }\end{array}$} & \multicolumn{5}{|c|}{ Composition of ash (\%) } \\
\hline $\mathrm{C}$ & \multicolumn{2}{|c|}{48,67} & $\mathrm{CO}_{3}^{-}$ & 4,5 & & $\mathrm{CaO}$ & 4,57 \\
\hline $\mathrm{H}$ & \multicolumn{2}{|c|}{5,45} & $\mathrm{SO}_{3}^{-}$ & 3,4 & & $\mathrm{MgO}$ & 3,25 \\
\hline $\mathrm{O}$ & \multicolumn{2}{|c|}{42,50} & $\mathrm{Cl}^{-}$ & 3,3 & & $\mathrm{Na}_{2} \mathrm{O}$ & 0,21 \\
\hline $\mathrm{S}$ & \multicolumn{2}{|c|}{0,04} & $\mathrm{P}_{2} \mathrm{O}_{6}$ & 3,0 & & $\mathrm{~K}_{2} \mathrm{O}$ & 23,74 \\
\hline $\mathrm{N}$ & \multicolumn{2}{|c|}{0,45} & $\mathrm{SiO}_{2}$ & 49, & & Others & 4,32 \\
\hline $\mathrm{Cl}$ & \multicolumn{2}{|c|}{0,23} & $\mathrm{Fe}_{2} \mathrm{O}_{3}$ & 0,2 & & & \\
\hline Ash & \multicolumn{2}{|c|}{2,76} & $\mathrm{Al}_{2} \mathrm{O}_{3}$ & 0,2 & & & \\
\hline
\end{tabular}

Miscanthus X Giganteus (MxG) is one of the most promising biomass crops for energy utilization. It's a renewable resource with almost net $\mathrm{CO}_{2}$ emission since carbon is completely fixed during the growth especially for $\mathrm{C} 4$ plants like MxG. Moreover, $\mathrm{MxG}$ present some advantages which are favourable for its valorisation in different ways (combustion, pyrolysis, gasification) in order to produce bio-oils, bio-fuels or hydrogen:

- MxG is a hardy perennial grass producing very high yields of bamboo like cane up to $4 \mathrm{~m}$ tall. The yields found in the literature ranged from 15 to $40 \mathrm{t} / \mathrm{ha}$.

- Starting from the same rhizome, MxG can be harvested all the year during twenty years and content less than $15 \%$ moisture if the harvesting is done in march. MxG is an environmentally friendly crop which requires little or no pesticide or fertiliser.

- MxG can be cultivated in all type of ground ( $\mathrm{pH}$ between 5 and 7.5 for example).

- MxG contains an average of $2 \%$ of mineral part, and not more than $0.2 \%$ of elemental sulphur (Table 1).

- In term of vegetable structure, $\mathrm{MxG}$ is well organized and contains $43 \%$ of cellulose. The calorific power of MxG is the half of the petroleum one (1TEP $\approx 2 t \mathrm{MxG})$ and calorific value of $16400 \mathrm{kj} / \mathrm{kg}$.

The aim of this work is to obtain synthesis gas from biomass gasification among five ways (Fig.1.). Hot gas conditioning is achieved by passing the raw gasifier product gas over a solid catalyst in a fluidised-bed (or a fixed-bed) under temperature and pressure conditions that essentially match those of the gasifier. Air gasification reported higher efficiency being achieved by lower oxygen consumption, better heat recovery and higher carbon conversion compared to a process based on noncatalytic techniques. The thermal cracking of the hydrocarbons is also Fig.1. Gasification process possible; however, this method is not considered a feasible option as it requires high temperatures $\left(>1100{ }^{\circ} \mathrm{C}\right)$ to achieve high cleaning efficiency and it also produces soot ${ }^{4}$. 
Fig.2. Syngas conversion processes

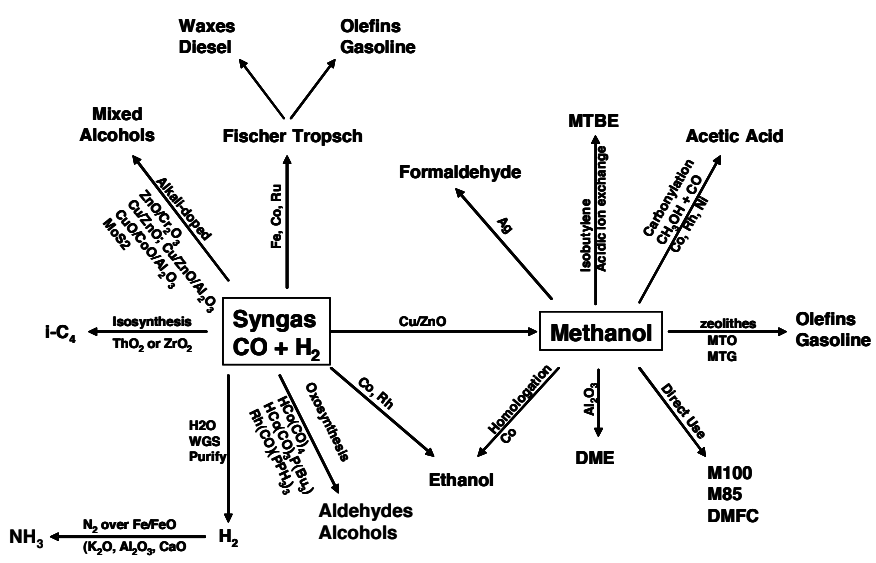

As the raw gas passes over the catalyst, the hydrocarbons may be reformed on a catalyst surface with either steam or carbon dioxide or both to produce additional carbon monoxide and hydrogen ${ }^{4}$.

From syngas, we can produce different compounds (Fig.2.). Either increase the yield of $\mathrm{H}_{2}$ using water gas shift reaction, then production of ammonia or methanol synthesis or production of biohydrocarbon by Fischer Tropsch synthesis.

The experiments were carried out in a fluidised-bed gasifer in catalytic conditions with water steam flow ${ }^{5,6}$. The biomass is continuously fed inside the system (Fig.3.) and gases are cleaning by cyclone with ceramic candle filter. Water and organic vapours (tars) are condensed by a cooling system. The fluidising medium is steam, the flow rate is controlled by a water dosing pump positioned upstream the steam generator.

The olivine affects the activity of the tars decomposition reactions, avoid carbon deposition on the surface by his positive catalytic role of iron and keep good mechanical intensity after calcination and high temperature reactions ${ }^{1,5,6}$. Thats why the fluidized bed consisted of $3 \mathrm{~kg}$ of $0.48 \mathrm{~mm}$ olivine particles of $2500 \mathrm{~kg} \cdot \mathrm{m}^{-3}$ density.

$\mathrm{MxG}$ was provided in form of pellets

Fig.3. Experimental system

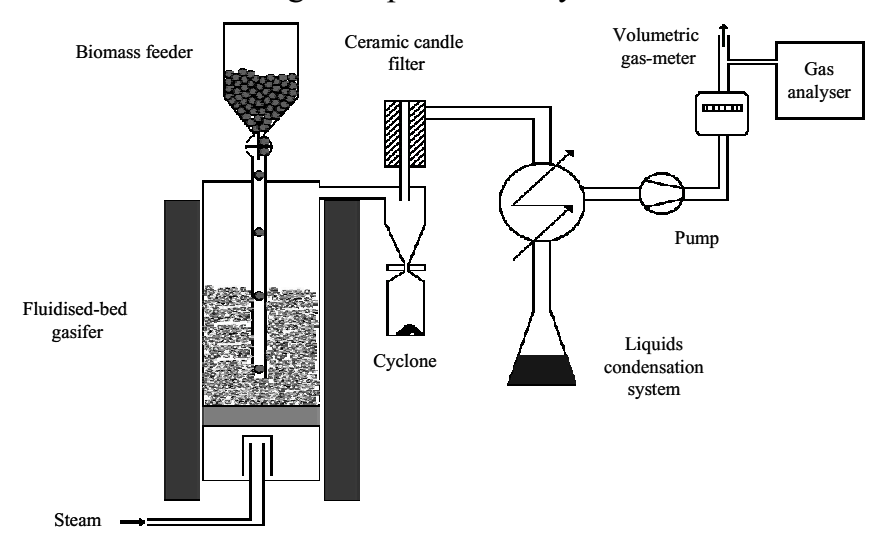
(diameter: $8 \mathrm{~mm}$ ). The pellets were too large to obtain a constant flow; therefore they were crushed in order to obtain a mixture of powder and crushed pellets. Then, the biomass is feed continuously inside the fluidised bed. For each gasification run, the biomass feed rate was fixed between 7 and 8 g.min ${ }^{-1}$.

The amount of the condensed organic material with water is determined by weighting. The quantity of dry gas produced is measured by a volumetric gas-meter. The concentrations of the dry gas are continuously monitored: $\mathrm{CO}, \mathrm{CO}_{2}$ and $\mathrm{CH}_{4}$ with an infrared analyser and $\mathrm{H}_{2}$ with a thermal conductivity detector. The quantity of char is obtained by determination of $\mathrm{CO}$ and $\mathrm{CO}_{2}$ after burning air with the whole carbonaceous residue trapped inside the reactor at the end of each gasification run.

The experimental runs with olivine were performed at three different temperatures $\left(815^{\circ} \mathrm{C}\right.$, $860^{\circ} \mathrm{C}$ and $880^{\circ} \mathrm{C}$ ). The time of each runs is 60 minutes. 
The evolution of gas amounts (Fig.4.) (calculated considering the carrier gas i.e. $\mathrm{N}_{2}$ ) is carry out during the run at $880^{\circ} \mathrm{C}$. The gasification occurs before 60 minutes and after the combustion takes place to determine the char content by measure of $\mathrm{CO}_{2}$ and $\mathrm{CO}$. The flow of gases is irregular because the flow of $\mathrm{MxG}$ is not constant and involves variation of pressure in reactor. This point will be improved in the future by optimising the $\mathrm{MxG}$ particle size.

The distribution of gases (Fig.5.) shows different yield of gases. The percentages are calculated without $\mathrm{N}_{2}$. The amount of $\mathrm{H}_{2}$ is higher than $40 \%$ and increases with temperature while $\mathrm{CH}_{4}, \mathrm{CO}_{2}$ and $\mathrm{CO}$ contents decrease. $\mathrm{CO}$ amount is about $25 \%$. We have good $\mathrm{H}_{2} / \mathrm{CO}$ ratio for methanol synthesis.

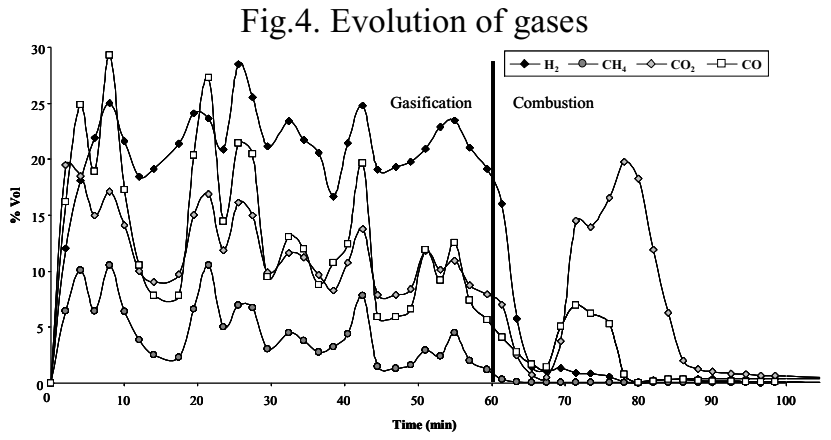

Fig.5. Distribution of gases

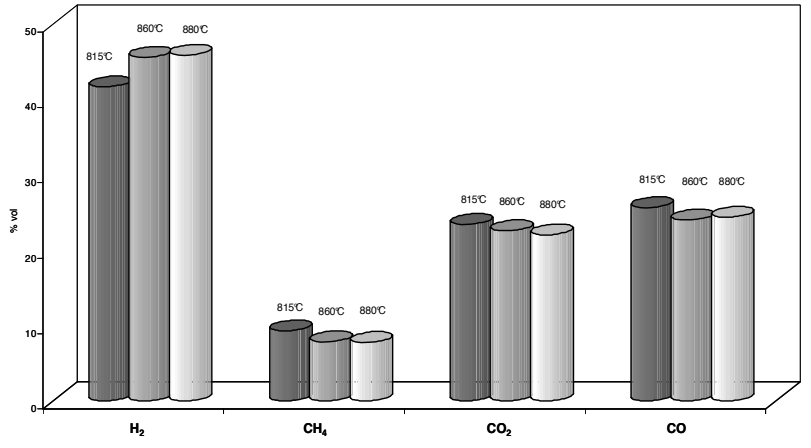

The experimental results show that Miscanthus $\mathrm{X}$ Giganteus is suitable for gasification. About $1.1 \mathrm{~N} \cdot \mathrm{m}^{3} \cdot \mathrm{kg}^{-1}$ (biomass) of gases are obtained, with $\mathrm{H}_{2}$ content higher than $40 \%$ and about $25 \%$ of $\mathrm{CO}$ by volume. This cleaning gas with this specification is suitable for industrial applications, both for highly efficient electricity production and as a feedstock for chemical synthesis like methanol synthesis. However, problems of particle size of $\mathrm{MxG}$ are unfavourable for the flow steadiness. These experiments are preliminary for $\mathrm{MxG}$. Modifications can be made to increase the production of $\mathrm{H}_{2}$ by the addition of a nickel based catalyst ${ }^{4}$, because interesting results have been obtained with $\mathrm{Ni}$ /olivine in the gasification of wood ships ${ }^{7}$.

1. S. Rapagnà, N. Jand and P.U. Foscolo: Hydrogen Energy, volume 23. (1998) 551-557

2. G. Hu, S. Xu, S. Li, C. Xiao, S. Liu: Fuel Processing Technology, volume 87. (2006) 375-382

3. L. Wei, S. Xu, L. Zhang, C. Liu, H. Zhu, S. Liu: Hydrogen Energy, volume 32. (2007) 24-31

4. D. Sutton, B. Kelleher and J.R.H. Ross: Fuel Processing Technology, volume 73. (2001) 155-173

5. S. Rapagnà, N. Jand, A. Kiennemann and P.U. Foscolo: Biomass and bioenergy, volume 19. (2000) 187-197

6. R.N. Andre, F. Pinto, C. Franco, M. Dias, I. Gulyurtlu, M.A.A. Matos, I. abrita: Fuel, volume 84. (2005)

1635-1644

7. C. Pfeifer, R. Rauch, H. Hofbauer, D. Świerczyński, C. Courson and A. Kiennemann: Science in Thermal and

Chemical Biomass Conversion, volume 1. 